\title{
The interplay between stress and physical activity in the prevention and treatment of cardiovascular disease
}

\author{
Matthew A. Stults-Kolehmainen* \\ Department of Psychiatry, Yale Stress Center, Yale University Medical School, New Haven, CT, USA \\ *Correspondence: matthew.stults-kolehmainen@yale.edu \\ Edited by: \\ Daniel Boullosa, Universidade Católica de Brasília, Brazil
}

Keywords: exercise, distress, mental health, physical activity, stress, psychological, cardiovascular diseases

Cardiovascular disease (CVD) continues to menace developed and developing nations alike. However, in the United States alone, $40.5 \%$ of the population is projected to have CVD or a closely related disorder by 2030 (Heidenreich et al., 2011). Within the same time frame, costs associated with CVD are expected to balloon up to $\$ 818$ billion (Heidenreich et al., 2011). These societal strains are increasing parallel to rising mental health disorders and psychosocial stress (Centers for Disease Control, 2011). In this context, stress refers to both physical and emotional challenges, some of which may be transient and rather innocuous (e.g., final examinations, strenuous exercise) with potential positive adaptations. Other stress may be chronic and uncontrollable (e.g., caregiving for a loved one with a terminal illness), which may produce excessive wear and tear, resulting in lasting and harmful insults to one's physical and mental health (McEwen, 2007). The American Psychological Association (APA) reports that $72 \%$ of Americans perceived that their stress increased or held steady from 2007 to 2011. Fourth fifths of this population reported an increase from 2010 to 2011 (American Psychological Association, 2012).

Unsurprisingly, there are wellestablished connections between stress and CVD. Indeed, stress provides an independent contribution to CVD outcomes (Vitaliano et al., 2002). Stress is linked to the pathogenesis of coronary heart disease (CHD) (Rozanski et al., 1999), incidence of acute myocardial infarctions (Rosengren et al., 2004) and worse survival from cardiac events (Kivimaki et al., 2002; Milani and Lavie, 2009). In one eye opening investigation, Milani and Lavie (2009) found that patients with high psychosocial stress in cardiac rehabilitation were almost 4 times as likely to die as those with low stress (22 vs. $5 \%$ ). The experience of distress, the emotional outcome of stress, also exacerbates the morbidity associated with CVD (Centers for Disease Control, 2011). Those who are objectively stressed, such as caretakers of those with chronic conditions, have higher resting heart rates, blood pressure, and greater incidence of metabolic syndrome (Vitaliano et al., 2002). Individuals reporting higher levels of stressful life events have higher scores on risk factors for CVD, such as smoking (Ansell et al., 2012), systemic inflammation (Puustinen et al., 2011) and obesity (Sinha and Jastreboff, 2013). They are nearly twice as likely to start using anti-hypertensive medication over time compared to less stressed individuals (Rod et al., 2009). Furthermore, those with CVD are often stressed by their condition-adjusting to a life with a long-term hardship (Bodenheimer et al., 2002). This demonstrates that stress both contributes toward disease and, reciprocally, emanates from the experience of disease, which leaves little doubt that mental health interventions are needed throughout the progression and treatment of CVD.

Given these findings, an effective prevention and/or treatment plan for CVD would also target stress, but would minimize additional side effects and healthcare costs. To this end, exercise interventions have proved effective. In terms of CVD pathology, exercise improves the odds of recuperating from stroke, reduces hypertension and diminishes symptoms of heart failure and CHD - in each case with few serious side effects (Kujala, 2009). Recent evidence finds that exercise is just as effective as or even more effective than medications. For instance, Naci and Ioannidis (2013) recently found that exercise had a stronger effect than anticoagulants and antiplatelets in the treatment of stroke. Moreover, there is convincing evidence that those who exercise are much less likely to develop CVD over time (Lee et al., 2012; Matheson et al., 2013). The same is true for depression and post-traumatic stress disorder (PTSD) (Leardmann et al., 2011). In a large military cohort, those who exercised at least 20 min of vigorous activity two times a week were $>40 \%$ less likely to develop new onset PTSD over $>3$ year period (Leardmann et al., 2011). Among those experiencing difficulties with stress, aerobic and resistance exercise has been effective in reducing stress-induced cardiac reactivity (King et al., 2002; Faulk and Bartholomew, 2012) and perceived stress (Wilcox et al., 2008), particularly when paired with healthy dietary changes (Imayama et al., 2011) and behavioral modification programming (Atlantis et al., 2004). Given the strong association between stress and CVD, is it possible that part of the health-enhancing power of exercise stems from its ability to mitigate the effects of stress (Milani and Lavie, 2009)? Extensive data supports the thought that physical activity (PA) buffers the relationship between stress and physical health problems (Gerber and Pühse, 2009; Emeny et al., 2012; Hamer, 2012; Rueggeberg et al., 2012). In other words, at high levels of stress, greater PA is associated with better health (Rueggeberg et al., 2012). Additionally, those who are physically fit are more resilient to the effects of stress, such as high work demands, resulting in less heart disease and associated mortality (Holtermann et al., 2010). 
Data from our own laboratory show that higher levels of moderate to vigorous exercise are associated with fewer complaints of cardiovascular problemsparticularly when stress is low (StultsKolehmainen et al., accepted). Under high levels of stress, however, higher levels of exercise were not related to better health, contradicting previous research (Rueggeberg et al., 2012). While PA-and more specifically, exercise-certainly have a salubrious effect on both psychosocial stress and CVD, and lifestyle interventions increasingly emphasize all forms of PA, I was left to wonder about the possible limitations of these health behaviors. One possible explanation for these discrepancies is that various forms of PA may have differential influence on the stress and CVD relationship (Fredman et al., 2006). PA, by definition, is any movement that results in energy expenditure, including occupational and spontaneous forms of locomotion (Garber et al., 2011). This is important because stressed populations, particularly laborers, may engage in moderate to high levels of occupational activity. Exercise, however, is typically performed with the intent of increasing physical fitness. Aside from athletes, military personnel and physical education students, it is usually considered recreational and is completed during one's leisure time. Therefore, it is possible that quantifications of exercise simply capture the luxury of having more time for rest and relaxation (Iwasaki et al., 2001). A preponderance of evidence would support the observations that those with less leisure are more frequently stressed, but also that those who are stressed typically have less leisure time (Fredman et al., 2006; Lutz et al., 2007).

Consequently, in the pursuit of better health, stress may have the upper hand over one's ability to engage in healthful levels of PA (Salmon, 2001). In fact, Rafer Lutz established that stress has a stronger effect on PA than the reverse order of influence (Lutz et al., 2007). This was the first and only prospective design with the specific aim of untangling these effects. Lutz, John Bartholomew and I later published data that suggested that those who are in earlier stages-of-change for exercise (i.e., pre-contemplators, contemplators) are most vulnerable to this effect (Lutz et al., 2010). This association does not appear to be limited to non-habituated exercisers, however. In our recent systematic review, Rajita Sinha and I found that $>85 \%$ of prospective studies examining the association of stress and PA/exercise reported an inverse relationship between these two constructs. In other words, the experience of high mental stress predicted less PA. Several studies used sophisticated designs to objectively capture periods of greater stress and examine future levels of PA or exercise (Griffin et al., 1993; Steptoe et al., 1996; Vitaliano et al., 1998; Roemmich et al., 2003; Oaten and Cheng, 2005; Smith et al., 2005; Sherman et al., 2009). However, only one investigation employed a true experimental design and manipulated an acute mental stressor (Roemmich et al., 2003). In this study, children participated in two conditions, the order of which was randomly selected. In the stress condition, these subjects were required to give a prepared talk on a social topic. This task induced a moderate to strong stress response, which was followed by the opportunity to be either physically active (riding a bicycle) or remain sedentary. Behavioral responses were compared to changes observed within a passive reading control condition. While responses subjective stress were not related to changes in exercise $(r=-0.19)$, children were less likely to expend energy after the stress condition compared to the control (a 21\% difference in total minutes of activity). Total energy expenditure was also lower in the stress condition. Also examining this outcome, Smith et al. (2005) found approximately a $1000 \mathrm{kcal}$ difference of weekly activity in a cohort of parents with a child who recently received a cancer diagnosis vs. parents of a healthy control child. Effects sizes for this association were large: 1.71 (Cohen's d) at diagnosis and 1.13 at a 3-month follow up. Such differences were due to less PA and more sedentary behavior, such as TV viewing. Given the long waits in doctors' offices to which these parents are subject, this is not surprising. In another longitudinal case-control study, caregivers had more stress and less frequent exercise bouts over two time points compared to matched controls (Vitaliano et al., 1998).
Following students before and during a final examinations period is a highly convenient method to observe potential influences of stress on health behaviors (Griffin et al., 1993; Steptoe et al., 1996; Oaten and Cheng, 2005; Sherman et al., 2009). In two cases, control groups have been utilized to determine whether other factors could explain changes in PA, such as the weather (Steptoe et al., 1996; Oaten and Cheng, 2005). These studies have identified significant declines in PA compared to controls during examinations, and such changes are due to less frequency, duration, and perceived ease of exercise. In an interesting permutation on this design, Sherman (Sherman et al., 2009) found that PA declined across a 14-day period that terminated with students' most stressful examination-a medium effect ( $p=$ $\left.0.03, d=0.62 ; \eta^{2}=0.26\right)$. Unfortunately, none of these studies looked at changes in PA after the completion of a stressful examination period or over multiple cycles of examinations, which would provide an additional insight on the dynamic effects of stress on exercise behavior. A rebound in PA after a stressful frame of time would complement existing data. Nevertheless, when viewed collectively, the published data substantiate the notion that both acute and transient or chronic life stressors have an impact on facets of PA.

These findings have direct implications for clinicians interested in improving CVD outcomes. Exercise is effective for treating both CVD and stress, but the patient would benefit from a treatment plan that goes beyond a prescription of exercise and "usual care." Navigating the complexities of a more active lifestyle is stressful in itself, particularly for the uninitiated (StultsKolehmainen and Sinha, 2013). Second, those who are chronically stressed experience both poor recovery from exercise and derive less affective benefits, placing them at risk for dropout early after initiation of an exercise routine (Stults-Kolehmainen and Bartholomew, 2012). Exercise cannot help those who do not adhere to a structured regimen, and stressed populations are at risk for drop out and poor compliance with their doctor's prescriptions. For instance, depressed cardiac rehabilitation patients are less likely to adhere to an exercise program; coming 
to fewer sessions and dropping out at high rates (Glazer et al., 2002). As a metaphor, the sun-scorched plant benefits from water, but inordinate heat will also evaporate the new moisture. Only when shade is introduced can full restoration occur. In a similar light, the human organism needs relief from stress to effectively take advantage of exercise. The combination of PA and stress management would likely have a synergistic effect. In a randomized controlled trial, Blumenthal et al. (2005) demonstrated that exercise training and stress management groups significantly improved flow-mediated arterial dilation and other clinical outcomes compared to a third group receiving only usual care. They did not test the utility of both exercise and stress management combined, which has been successfully tested by Ornish et al. (1998). Their lifestyle intervention resulted in 50\% reductions in the re-occurrence of cardiac events. Given this progression, a logical follow-up study should fully intertwine stress management procedures, such as mindfulnessbased stress reduction (MBSR) (Ludwig and Kabat-Zinn, 2008), as part of the exercise regimen. Mindfulness practices can be conducted during movement (i.e., controlled breathing and contractions with proper alignment), during rest periods (e.g., focusing on changing internal states) and directly following a workout (e.g., sensing stillness and the process of unwinding). Such a combination may enhance physical recovery (StultsKolehmainen and Bartholomew, 2012), boost affective valence (increase positive emotions), and reinforce exercise behavior resulting in more effective treatment with time and cost savings.

Stress is a common denominator underlying CVD and the lack of PA. It independently contributes to pathologies of the cardiovascular system, exacerbates distress associated with these problems and impedes one's progress toward a healthier lifestyle. As this is a complicated set of relationships, I would argue that novel therapeutic regimens are needed to address the manifestation of stress at multiple levels. Fully melding exercise interventions with proven stress management techniques, such as MBSR, would be a useful strategy.

\section{REFERENCES}

American Psychological Association. (2012). Stress in America [Online]. Available online at: www.stressinamerica.org (Accessed November 7, 2013).

Ansell, E. B., Gu, P. H., Tuit, K., and Sinha, R. (2012). Effects of cumulative stress and impulsivity on smoking status. Hum. Psychopharmacol. 27, 200-208. doi: 10.1002/hup.1269

Atlantis, E., Chow, C. M., Kirby, A., and Singh, M. F. (2004). An effective exercise-based intervention for improving mental health and quality of life measures: a randomized controlled trial. Prev. Med. 39, 424-434. doi: 10.1016/j.ypmed.2004. 02.007

Blumenthal, J. A., Sherwood, A., Babyak, M. A., Watkins, L. L., Waugh, R., Georgiades, A., et al. (2005). Effects of exercise and stress management training on markers of cardiovascular risk in patients with ischemic heart disease - A randomized controlled trial. JAMA 293, 1626-1634. doi: 10.1001/jama.293.13. 1626

Bodenheimer, T., Lorig, K., Holman, H., and Grumbach, K. (2002). Patient self-management of chronic disease in primary care. JAMA 288, 2469-2475. doi: 10.1001/jama.288.19.2469

Centers for Disease Control. (2011). Mental illness surveillance among adults in the united states. MMWR Surveill. Summ. 60, 1-30. Available online at: http://origin.glb.cdc.gov/mmWR/preview/ mmwrhtml/su6003al.htm

Emeny, R. T., Lacruz, M. E., Baumert, J., Zierer, A., Von Eisenhart, R. A., Autenrieth, C. S., et al. (2012). Job strain associated CRP is mediated by leisure time physical activity: results from the MONICA/KORA study. Brain Behav. Immun. 26, 1077-1084. doi: 10.1016/j.bbi.2012.07.004

Faulk, K. E., and Bartholomew, J. B. (2012). The moderating effect of physical activity on cardiovascular reactivity following single fat feedings. Psychophysiology 49, 145-149. doi: 10.1111/j.14698986.2011.01283.x

Fredman, L., Bertrand, R. M., Martire, L. M., Hochberg, M., and Harris, E. L. (2006). Leisuretime exercise and overall physical activity in older women caregivers and non-caregivers from the caregiver-SOF study. Prev. Med. 43, 226-229. doi: 10.1016/j.ypmed.2006.04.009

Garber, C. E., Blissmer, B., Deschenes, M. R., Franklin, B. A., Lamonte, M. J., Lee, I. M., et al. (2011). Quantity and quality of exercise for developing and maintaining cardiorespiratory, musculoskeletal, and neuromotor fitness in apparently healthy adults: guidance for prescribing exercise. Med. Sci. Sports Exerc. 43, 1334-1359. doi: 10.1249/MSS.0b013e318213fefb

Gerber, M., and Pühse, U. (2009). Do exercise and fitness protect against stress-induced health complaints? A review of the literature. Scand. J. Public Health 37, 801-819. doi: 10.1177/1403494809350522

Glazer, K. M., Emery, C. F., Frid, D. J., and Banyasz, R. E. (2002). Psychological predictors of adherence and outcomes among patients in cardiac rehabilitation. J. Cardiopulm. Rehabil. 22, 40-46. doi: 10.1097/00008483-200201000-00006

Griffin, K. W., Friend, R., Eitel, P., and Lobel, M. (1993). Effects of environmental demands, stress, and mood on health practices. J. Behav. Med. 16, 643-661. doi: 10.1007/BF00844724

Hamer, M. (2012). Psychosocial stress and cardiovascular disease risk: the role of physical activity. Psychosom. Med. 74, 896-903. doi: 10.1097/PSY.0b013e31827457f4

Heidenreich, P. A., Trogdon, J. G., Khavjou, O. A., Butler, J., Dracup, K., Ezekowitz, M. D., et al. (2011). Forecasting the future of cardiovascular disease in the United States: a policy statement from the American Heart Association. Circulation 123, 933-944. doi: 10.1161/CIR.0b013e31820a55f5

Holtermann, A., Mortensen, O. S., Burr, H., Sogaard, K., Gyntelberg, F., and Suadicani, P. (2010). Physical demands at work, physical fitness, and 30-year ischaemic heart disease and allcause mortality in the Copenhagen Male Study. Scand. J. Work Environ. Health 36, 357-365. doi: 10.5271/sjweh.2913

Imayama, I., Alfano, C. M., Kong, A., Foster-Schubert, K. E., Bain, C. E., Xiao, L. R., et al. (2011). Dietary weight loss and exercise interventions effects on quality of life in overweight/obese postmenopausal women: a randomized controlled trial. Int. J. Behav. Nutr. Phys. Act. 8, 1-12. doi: 10.1186/14795868-8-118

Iwasaki, Y., Zuzanek, J., and Mannell, R. C. (2001). The effects of physically active leisure on stresshealth relationships. Can. J. Public Health 92, 214-218.

King, A. C., Baumann, K., O'Sullivan, P., Wilcox, S., and Castro, C. (2002). Effects of moderateintensity exercise on physiological, behavioral, and emotional responses to family caregiving: a randomized controlled trial. J. Gerontol. A Biol. Sci. Med. Sci. 57, M26-M36. doi: 10.1093/gerona/57.1.M26

Kivimaki, M., Leino-Arjas, P., Luukkonen, R., Riihimaki, H., Vahtera, J., and Kirjonen, J. (2002). Work stress and risk of cardiovascular mortality: prospective cohort study of industrial employees. Br. Med. J. 325, 857-860. doi: 10.1136/bmj.325.7369.857

Kujala, U. M. (2009). Evidence on the effects of exercise therapy in the treatment of chronic disease. Br. J. Sports Med. 43, 550-555. doi: 10.1136/bjsm.2009.059808

Leardmann, C. A., Kelton, M. L., Smith, B., Littman, A. J., Boyko, E. J., Wells, T. S., et al. (2011). Prospectively assessed posttraumatic stress disorder and associated physical activity. Public Health Rep. 126, 371-383.

Lee, I. M., Shiroma, E. J., Lobelo, F., Puska, P., Blair S. N., Katzmarzyk, P. T., et al. (2012). Effect of physical inactivity on major non-communicable diseases worldwide: an analysis of burden of disease and life expectancy. Lancet 380, 219-229. doi: 10.1016/S0140-6736(12)61031-9

Ludwig, D. S., and Kabat-Zinn, J. (2008). Mindfulness in medicine. JAMA 300, 1350-1352. doi: 10.1001/jama.300.11.1350

Lutz, R. S., Lochbaum, M. R., Lanning, B., Stinson, L. G., and Brewer, R. (2007). Cross-lagged relationships among leisure-time exercise and perceived stress in blue-collar workers. J. Sport Exerc. Psychol. 29, 687-705.

Lutz, R. S., Stults-Kolehmainen, M. A., and Bartholomew, J. B. (2010). Exercise caution when 
stressed: stages of change and the stress-exercise participation relationship. Psychol. Sport Exerc. 11, 560-567. doi: 10.1016/j.psychsport.2010.06.005

Matheson, G., Klügl, M., Engebretsen, L., Bendiksen, F., Blair, S., Börjesson, M., et al. (2013). Prevention and management of non-communicable disease: the IOC consensus statement, Lausanne 2013. Sports Med. 43, 1075-1088. doi: 10.1007/s40279013-0104-3

McEwen, B. S. (2007). Physiology and neurobiology of stress and adaptation: central role of the brain. Physiol. Rev. 87, 873-904. doi: 10.1152/physrev.00041.2006

Milani, R. V., and Lavie, C. J. (2009). Reducing psychosocial stress: a novel mechanism of improving survival from exercise training. Am. J. Med. 122, 931-938. doi: 10.1016/j.amjmed.2009.03.028

Naci, H., and Ioannidis, J. P. A. (2013). Comparative effectiveness of exercise and drug interventions on mortality outcomes: meta-epidemiological study. BMJ 347. doi: 10.1136/bmj.f5577. [Epub ahead of print].

Oaten, M., and Cheng, K. (2005). Academic examination stress impairs self-control. J. Soc. Clin. Psychol. 24, 254-279. doi: 10.1521/jscp.24.2.254.62276

Ornish, D., Scherwitz, L. W., Billings, J. H., Gould, K. L., Merritt, T. A., Sparler, S., et al. (1998). Intensive lifestyle changes for reversal of coronary heart disease. JAMA 280, 2001-2007. doi: 10.1001/jama.280.23.2001

Puustinen, P. J., Koponen, H., Kautiainen, H., Mantyselka, P., and Vanhala, M. (2011). Psychological distress and C-reactive protein: do health behaviours and pathophysiological factors modify the association? Eur. Arch. Psychiatry Clin. Neurosci. 261, 277-284. doi: 10.1007/s00406-010-0134-x

Rod, N. H., Gronbaek, M., Schnohr, P., Prescott, E., and Kristensen, T. S. (2009). Perceived stress as a risk factor for changes in health behaviour and cardiac risk profile: a longitudinal study. J. Intern. Med. 266, 467-475. doi: 10.1111/j.13652796.2009.02124.x

Roemmich, J. N., Gurgol, C. M., and Epstein, L. H. (2003). Influence of an interpersonal laboratory stressor on youths' choice to be physically active. Obes. Res. 11, 1080-1087. doi: 10.1038/oby. 2003.148
Rosengren, A., Hawken, S., Ounpuu, S., Sliwa, K., Zubaid, M., Almahmeed, W. A., et al. (2004). Association of psychosocial risk factors with risk of acute myocardial infarction in 11,119 cases and 13,648 controls from 52 countries (the INTERHEART study): case-control study. Lancet 364, 953-962. doi: 10.1016/S0140-6736(04) 17019-0

Rozanski, A., Blumenthal, J. A., and Kaplan, J. (1999). Impact of psychological factors on the pathogenesis of cardiovascular disease and implications for therapy. Circulation 99, 2192-2217. doi: 10.1161/01.CIR.99.16.2192

Rueggeberg, R., Wrosch, C., and Miller, G. E. (2012). The different roles of perceived stress in the association between older adults' physical activity and physical health. Health Psychol. 31, 164-171. doi: 10.1037/ a0025242

Salmon, P. (2001). Effects of physical exercise on anxiety, depression, and sensitivity to stress: a unifying theory. Clin. Psychol. Rev. 21, 33-61. doi: 10.1016/S0272-7358(99)00032-X

Sherman, D. K., Bunyan, D. P., Creswell, J. D., and Jaremka, L. M. (2009). Psychological vulnerability and stress: the effects of self-affirmation on sympathetic nervous system responses to naturalistic stressors. Health Psychol. 28, 554-562. doi: 10.1037/a0014663

Sinha, R., and Jastreboff, A. M. (2013). Stress as a common risk factor for obesity and addiction. Biol. Psychiatry 73, 827-835. doi: 10.1016/j.biopsych.2013.01.032

Smith, A. W., Baum, A., and Wing, R. R. (2005). Stress and weight gain in parents of cancer patients. Int. J. Obes. 29, 244-250. doi: 10.1038/sj.ijo. 0802835

Steptoe, A., Wardle, J., Pollard, T. M., Canaan, L., and Davies, G. J. (1996). Stress, social support and health-related behavior: a study of smoking, alcohol consumption and physical exercise. J. Psychosom. Res. 41, 171-180. doi: 10.1016/00223999(96)00095-5

Stults-Kolehmainen, M. A., and Bartholomew, J. B. (2012). Psychological stress impairs short-term muscular recovery from resistance exercise. Med. Sci. Sports Exerc. 44, 2220-2227. doi: 10.1249/MSS.0b013e31825f67a0
Stults-Kolehmainen, M. A., and Sinha, R. (2013). The effects of stress on physical activity and exercise: a systematic review. Sports Med. 41. doi: 10.1007/s40279-013-0090-5. [Epub ahead of print].

Stults-Kolehmainen, M. A., Sinha, R., and Tuit, K. (accepted). Lower cumulative stress is associated with better health for physically active individuals in the community. Stress.

Vitaliano, P. P., Scanlan, J. M., Ochs, H. D., Syrjala, K., Siegler, I. C., and Snyder, E. A. (1998). Psychosocial stress moderates the relationship of cancer history with natural killer cell activity. Ann. Behav. Med. 20, 199-208. doi: 10.1007/BF0288 4961

Vitaliano, P. P., Scanlan, J. M., Zhang, J., Savage, M. V., Hirsch, I. B., and Siegler, I. C. (2002). A path model of chronic stress, the metabolic syndrome, and coronary heart disease. Psychosom. Med. 64, $418-435$.

Wilcox, S., Dowda, M., Leviton, L. C., BartlettPrescott, J., Bazzarre, T., Campbell-Voytal, K., et al. (2008). Active for life - final results from the translation of two physical activity programs. Am. J. Prev. Med. 35, 340-351. doi: 10.1016/j.amepre.2008.07.001

Received: 31 October 2013; accepted: 08 November 2013; published online: 27 November 2013.

Citation: Stults-Kolehmainen MA (2013) The interplay between stress and physical activity in the prevention and treatment of cardiovascular disease. Front. Physiol. 4:346. doi: 10.3389/fphys.2013.00346

This article was submitted to Clinical and Translational Physiology, a section of the journal Frontiers in Physiology.

Copyright (C) 2013 Stults-Kolehmainen. This is an open-access article distributed under the terms of the Creative Commons Attribution License (CC BY). The use, distribution or reproduction in other forums is permitted, provided the original author(s) or licensor are credited and that the original publication in this journal is cited, in accordance with accepted academic practice. No use, distribution or reproduction is permitted which does not comply with these terms. 